\title{
Sialolithiasis in the Parotid Duct - An Unusual Case Report
}

\author{
Soumi Samuel ${ }^{1}$, Vabitha Shetty ${ }^{2}$ \\ ${ }^{1}$ Department of Oral and Maxillofacial Surgery, A.B. Shetty Memorial Institute of Dental \\ Sciences, Nitte (Deemed to Be University), Mangalore, Karnataka, India. ${ }^{2}$ Department of \\ Paediatric and Preventive Dentistry, A.B. Shetty Memorial Institute of Dental Sciences, Nitte \\ (Deemed to Be University), Mangalore, Karnataka, India.
}

\section{INTRODUCTION}

Sialoliths are calcified structures that develop within the salivary duct system. It is believed that they arise due to the deposition of calcium salts around a nidus of debris within the ductal lumen. The cause of sialoliths is unclear but their formation can be promoted by chronic sialadenitis and partial obstruction. Sialoliths most commonly occur in the submandibular ductal system owing to the composition of saliva and the direction of the duct. It is rare to find a sialolith in the parotid duct. Major gland sialoliths cause episodic pain and swelling of the affected gland, especially at mealtimes.

This article highlights a case of sialolithiasis associated with secondary infection and pus discharge in a patient who reported to the outpatient department (OPD) of Oral \& Maxillofacial Surgery.

Sialolithiasis (calculi, salivary stones) is the occurrence of calcareous concretions in the salivary glands or ducts. They are formed by the deposition of calcium salts around a central nidus. ${ }^{1}$ The major salivary glands and the ducts of the head and neck contribute to the formation of sialolithiasis. These include the parotid glands, submandibular glands, and sublingual glands. The most common cause of salivary gland swelling is sialolithiasis with a reported incidence of 1 in 10000 to 1 in $30000 .^{2}$

Submandibular glands (up to $90 \%$ of cases) contribute to the formation of salivary stone followed by parotid glands (5 to $10 \%$ ). The least affected are sublingual gland and minor salivary glands. ${ }^{3}$

\section{PRESENTATION OF CASE}

A 47-year-old female reported to the OPD of Oral and Maxillofacial Surgery with a complaint of pain in the right parotid area for 3 days. Pain was severe and aggravated during meals. She also complained of a foul-smelling, distasteful secretion in the oral cavity on applying external pressure on the right parotid area. She complained of a similar pain in the right parotid area a month ago. On check up by a local dentist, analgesics were prescribed, and the pain subsided.
Corresponding Author: Dr. Vabitha Shetty, Capitol Apts, Flat No. 702, Kadri - 575003, Mangalore, Karnataka, India.

E-mail: docvabitha29@gmail.com

DOI: $10.14260 /$ jemds/2021/56

How to Cite This Article:

Samuel S, Shetty V. Sialolithiasis in the parotid duct - an unusual case report. J Evolution Med Dent Sci 2021;10(04):250252, DOI: $10.14260 /$ jemds/2021/56

Submission 22-09-2020,

Peer Review 26-11-2020,

Acceptance 03-12-2020,

Published 25-01-2021.

Copyright (C) 2021 Soumi Samuel et al. This is an open access article distributed under Creative Commons Attribution License [Attribution 4.0 International (CC BY 4.0)] 


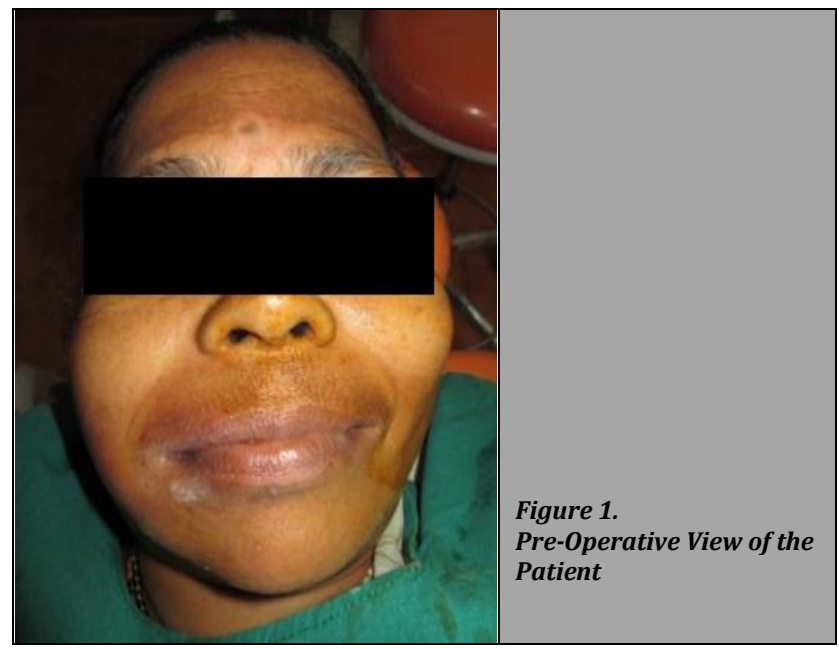

On examination, extra orally, there was a swelling of the right parotid area. The swelling was firm in consistency, tender on palpation with a local rise in temperature. The swelling measured $3 \times 3 \mathrm{~cm}$ extra orally located $1.5 \mathrm{~cm}$ anterior to the tragus. Intra orally, the site of the opening of the right parotid duct was swollen and inflamed. There was exudation of pus from the ductal opening. The pus was greyish-yellow in colour with no tinge of blood.

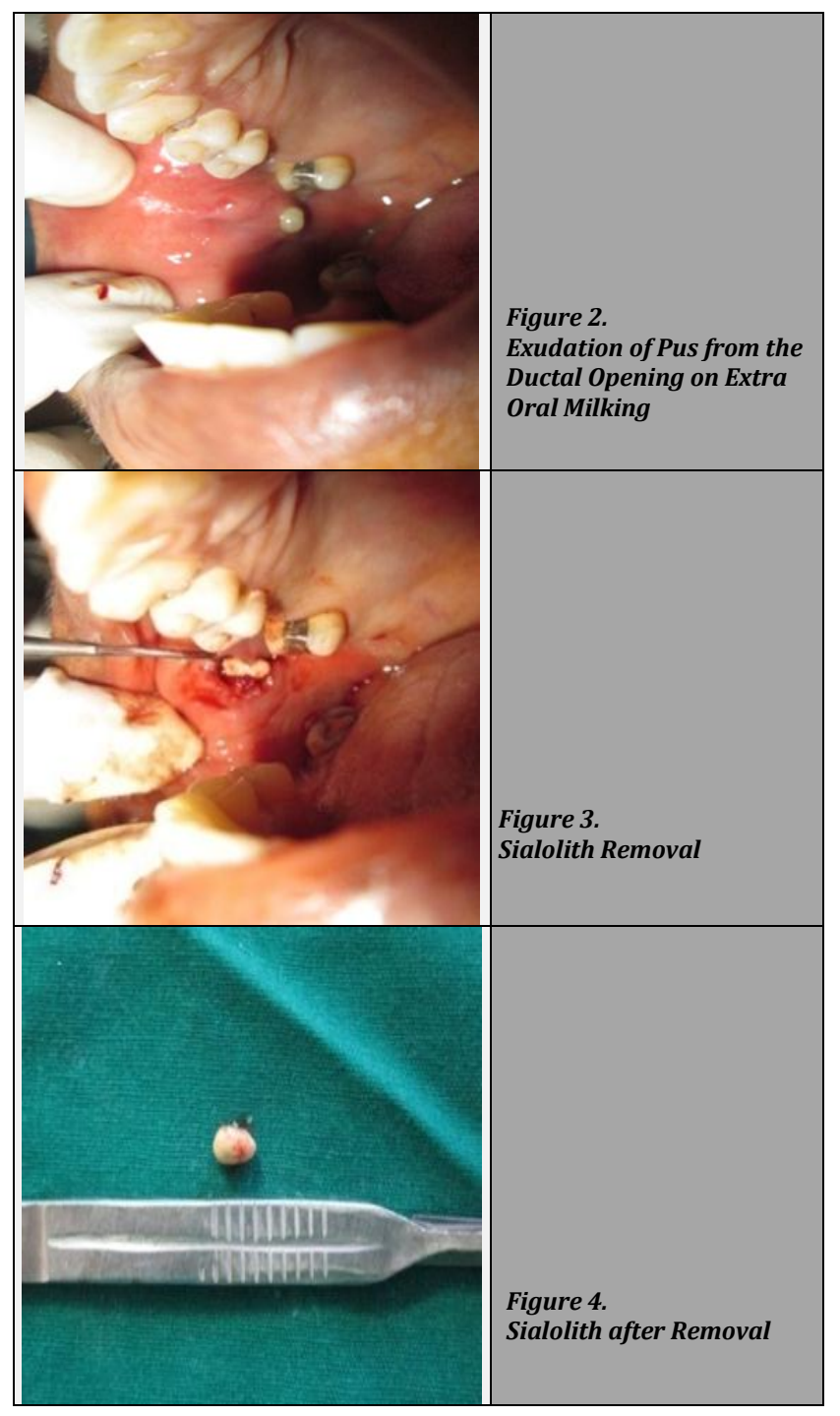

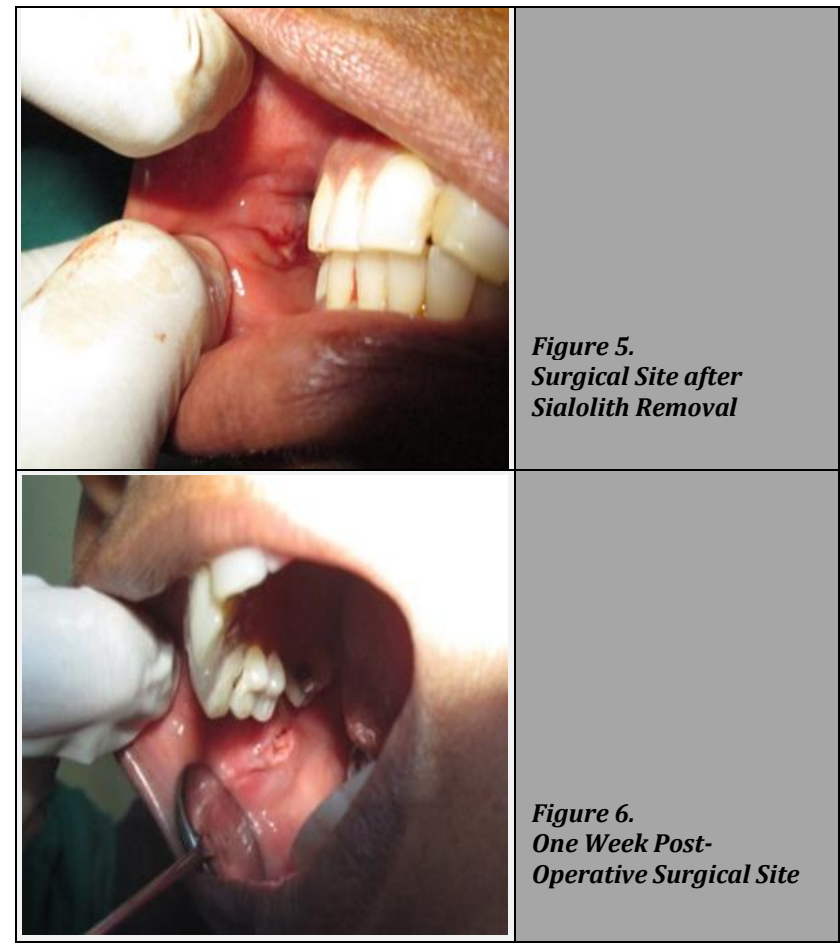

An ultrasonography (USG) was performed in the area, which revealed a grossly enlarged parotid duct with a site of hyperechoic foci on the anterior part of the duct. It was suspected to be a sialolith measuring $7.68 \mathrm{~mm}$ in diameter.

A posterior anterior puffed-cheek view was taken which showed the presence of the calculus in the right ramus area.

\section{DISCUSSION OF MANAGEMENT}

Patient was informed about the condition and treatment was discussed. Informed written consent was also taken. The sialolith was removed under local anaesthesia. An incision was placed just below the swelling intra orally and the ductal opening was exposed. Then, once the sialolith was spotted, it was removed using a curved haemostat. The area was left without suturing so as to drain any collected pus from the gland. The patient was put on antibiotics and discharged the day after surgery.

\section{DISCUSSION}

Calcified structures that develop within the salivary ductal system are termed as sialolith. They are thought to develop from deposition of calcium salts around a nidus of debris within the ductal lumen. Inspissated mucus, bacteria, ductal epithelial cells or foreign bodies can be the source of debris. Calcium deposition occurs in concentric layers.

The aetiology of sialoliths is unclear. Chronic sialadenitis and partial obstruction can lead to their formation. The systemic derangements in calcium and phosphorus metabolism have no contribution in their development. ${ }^{4}$

The occurrence of sialolith is most commonly seen in the submandibular gland and Wharton's duct. The contribution of obstructive salivary disease by sialolithiasis has been accounted for $66 \%$. Majority of cases are reported in the 
submandibular gland with only $5 \%-10 \%$ in parotid gland. The stones seen in parotid duct do not appear in radiographs. The stones visualised in parotid duct system are rarely calcified and are mostly mucous plugs. Strictures and kinks have $75.3 \%$ involvement in the parotid duct and are the second most common cause of obstructive sialadenitis. ${ }^{5}$ The parotid gland secretion is much less viscous because of the high protein content and because the course of the Stenson's duct is downward. Sialolith are most common in young and middle-aged adults but can affect all age groups. ${ }^{6}$ Conventional radiography, sialography and USG are the diagnostic aids used to assess sialolith. Calcified sialolith are not detected by conventional radiography until they are $60-70 \%$ calcified. At least $20 \%$ of submandibular and $50 \%$ of parotid stones are not identifiable on intraoral and panoramic radiography but can be detected by high resolution non contrast computed tomography (CT) scanning. In our study a posterior anterior puffed-cheek view was taken which showed the presence of the calculus in the parotid duct area.

The methods of management of sialolith can be conservative or surgical. Oral analgesia, hydration, local heat therapy and sialagogues to promote ductal secretions are proposed as conservative management. ${ }^{7}$ Parotid sialoliths can be endoscopically retrieved which has a high success rate and low postoperative complications. For sialoliths which are mobile and less than $5 \mathrm{~mm}$, interventional sialendoscopy is successful. ${ }^{8}$ Depending on the size and location, surgical intervention would be advocated for sialoliths which have failed a non-invasive management. ${ }^{9}$ The transoral ductal incision, external approaches, or a combined venture are the treatment options included for open surgical procedures. ${ }^{10}$

\section{FINAL DIAGNOSIS}

Bacterial Sialadenitis Secondary to Obstructive Sialolithiasis

\section{CONCLUSIONS}

Recurrent parotitis due to Stensen's duct obstruction is commonly caused by strictures or calculi. Sialolithiasis damages salivary glands by the obstruction of salivary flow. Back pressure and inflammation lead to fibrosis of the gland parenchyma. If the sialolith is of a long-standing type, the gland may undergo irreversible inflammation and fibrosis, which may not recover even when the sialolith is removed. So, it is essential that we diagnose the sialolith and remove it at the earliest before irreversible changes set in.

Financial or other competing interests: None.

Disclosure forms provided by the authors are available with the full text of this article at jemds.com.

\section{REFERENCES}

[1] Sivapathasundharam B. Shafer's textbook of Oral pathology. $8^{\text {th }}$ edn. Elsevier India 2016: p. 682.

[2] Huoh KC, Eisele DW. Etiologic factors in sialolithiasis. Otolaryngol Head Neck Surg 2011;145(6):935-9.

[3] McKenna JP, Bostock DJ, McMenamin PG. Sialolithiasis. Am Fam Physician 1987;36(5):119-25.

[4] Neville BW, Allen CM, Damm DD, et al. Oral and maxillofacial pathology. $1^{\text {st }}$ South Asia edn. Elsevier India 2012: p. 427.

[5] Sreetharan SS, Philip R. Unusual foreign body of parotid gland presenting as sialolithiasis. Case Reports in Otolaryngology 2012;2012:367349.

[6] Graziani F, Vano M, Cei S, et al. Unusual asymptomatic giant sialolith of submandibular gland: a clinical report. J Craniofac Surg 2006;17(3):549-52.

[7] Moghe S, Pillai A, Thomas S, et al. Parotid sialolithiasis. BMJ Case Rep 2012;2012:bcr2012007480.

[8] Capaccio P, Gaffuri M, Pignataro L. Sialendoscopy-assisted transfacial surgical removal of parotid stones. J Craniomaxillofac Surg 2014;42(8):1964-9.

[9] Daniel SJ, Kanaan A. Open surgical management of sialolithiasis. Operative Techniques Otolaryngology Head and Neck Surgery 2015;26(3):143-9.

[10] Samani M, Hills AJ, Holden AM, et al. Minimally-invasive surgery in the management of symptomatic parotid stones. Br J Oral Maxillofac Surg 2016;54(4):438-42. 